\title{
EN AW-5754 ve EN AW-5083 alüminyum alaşımlarının sürtünme karıştırma kaynağı ile birleştirilmelerinde kullanılan farklı takım geometrilerinin kaynaklı birleştirmeye etkilerinin araștırılması
}

\author{
Fatmagül TOLUN* \\ Balıkesir Üniversitesi, Balıkesir MYO, Motorlu Araçlar ve Ulaştırma Teknolojileri Bölümü, Balıkesir \\ Geliş Tarihi (Received Date): 30.10 .2019 \\ Kabul Tarihi (Accepted Date): 02.01.2020
}

$\ddot{O} \mathbf{z}$

Sürtünme karıştırma kaynă̆ı 1990'lı yılların başlarında ilk kez keşfedilmiştir. O yıllardan günümüze değin endüstride pek çok alanda kullanılmıştır. Sürtünme karıştırma kaynağı, aynı veya farklı özellikteki malzemelerin, ergitme sicaklı̆̆ının altındaki sıcaklıklarda birleştirilmesinde kullanılan, bir katı hal kaynak yöntemidir. Kaynak işlemi sırasında kullanılan takımlar kaynakl birleştirmenin metalurjik ve mekanik özelliklerini büyük oranda etkilemektedir. Takımların karıştırıcı uç geometrilerinin kaynakl birleştirmenin dayanımında önemli ölçüde etkisi bulunmaktadır. Bu çalışmada da, EN AW-5754 ve EN AW-5083 alüminyum alaşımları, $450 \mathrm{~d} /$ dak devir sayısında, $50 \mathrm{~mm} /$ dak ilerleme hızında 0 derecelik omuz açısıyla, vidalı, konik ve silindirik karıştırıcı uçlu takımlarla, sürtünme karıştırma kaynağı ile birleştirilmişlerdir. Kaynak işlemi sonrasında numunelere, çekme testleri ve mikrosertlik testleri yapılarak kaynaklı bağlantıların mekanik özellikleri incelenmiştir. Kaynaklı numunelerin optik mikroskop görüntüleri alınarak metalurjik yapılar incelenmiştir. Kaynaklı numunelere yapılan çekme testi sonuçlarına göre, en iyi kaynak dayanımını; 188,76 MPa lık kaynak mukavemeti ile vidal karıştırıcı uçla yapılan kaynaklı birleştirmeler göstermiştir. Ayrıca, mikro sertlik ve mikro yapı incelemeleri de bu sonucu desteklemektedir.

Anahtar kelimeler: Sürtünme karıştırma kaynağı, alüminyum alaşımları, takım geometrisi.

\footnotetext{
*Fatmagül TOLUN, ftolun@balikesir.edu.tr, http://orcid.org/0000-0001-7784-9115
} 


\title{
Investigation of the effects of different tool geometries on welded joining of EN AW-5754 and EN AW-5083 aluminum alloys with friction stir welding
}

\begin{abstract}
Friction stir welding was first discovered in the early 1990s. It has been used in many fields in the industry since then. Friction stir welding is a solid state welding method used for joining materials of the same or different properties at temperatures below the melting temperature. The tools used during the welding process greatly affect the metallurgical and mechanical properties of the welded joint. The stir tip geometries of the tools have a significant effect on the strenght of the welded joint. In this study, EN AW- 5754 and EN AW- 5083 aluminum alloys are joined with friction stir welding with screw stir tip, taper stir tip and cylindrical stir tip tools at 450 rpm traverse speed, 50 $\mathrm{mm} / \mathrm{min}$ progress speed, 0 degrees shoulder angle. After the welding process, mechanical properties of welded joints were examined by tensile tests and microhardness tests. Metallurgical structures of welded samples were examined by optical microscope images. According to the tensile test results of welded samples, welded joints with screw stir tip showed the best weld strength with a welding strength of $188.76 \mathrm{MPa}$. In addition, microhardness and microstructure tests support this result.
\end{abstract}

Keywords: Friction stir welding, aluminum alloys, tool geometry.

\section{Giriş}

Alüminyum alaşımları yoğunluklarının düşük olması, mukavemetlerinin yüksek olması, kolay şekillendirilebilmeleri, korozyon dirençlerinin iyi olması, dış şartlara karşı dirençli olmaları ve geri dönüşümlerinin kolay olması nedeniyle günümüzde endüstride pek çok alanda kullanılmaktadırlar. 5000 serisi alüminyum alaşımları; asıl alaşım elementi magnezyum olan Al-Mg alaşımlarıdır. Magnezyum oranı arttıkça sertlik ve mukavemet değerleri artmakta ve süneklik değerleri azalmaktadır. Bu alaşımlara 1sıl işlem uygulanamaz. Bu çalışmada kullanılan EN AW- 5754 ve EN AW- 5083 Al alaşımları, özellikle deniz suyu ve kimyasallara karşı yüksek korozyon dirençleri nedeniyle gemi ve inşa sanayinde, kimya sanayinde, otomotiv sanayinde ve basinçlı kapların yapımında tek başlarına veya bir arada yaygın olarak kullanılmaktadırlar [1,2]. Alüminyum alaşımlarının ergitme kaynak yöntemleri ile birleştirilmesinde, çatlak ve porozite oluşumu problemleri görülmektedir. Ayrıca; kaynak sonrasi sertlik ve mukavemet değerlerinde düşüş meydana gelmektedir. 1990'lı yılların başlarında, The Welding Institute (TWI) tarafından İngiltere'de geliştirilen ve patenti alınan sürtünme karıştırma kaynağı (SKK) ile yapılan birleştirmelerde bu problemlerin giderilebildiği görülmektedir. Alüminyum ve alaşımlarının SKK ile yapılan birleştirmelerinde; yüksek mukavemet değerleri, ideal bir kaynak profili ve daha pürüzsüz bir yüzey kalitesi görülmektedir [3,4,5,6].

Hafiflikleri, korozyon dirençleri ve yüksek mukavemet değerleri nedeniyle havacılık ve uzay endüstrisinde ve otomotiv endüstrisinde tercih edilen $\mathrm{Al}$ alaşımları gibi; $\mathrm{Mg}$ alaşımlarının, Ti alaşımlarının, kompozit malzemelerin ve polimer malzemelerin de; 
ergitme kaynak yöntemleriyle birleştirilmelerinde problemlerle karşılaşılmaktadır. $\mathrm{Bu}$ nedenle bu malzemelerin birleştirilmesinde de, SKK yöntemi kullanılmaktadır [7-14]. Bir katı hal kaynağı olan sürtünme karıştırma kaynağının, otomasyon kolaylığı, kısa kaynak süresi ve minimum yüzey hazırlama gibi pek çok avantajı bulunmaktadır. Bu yöntemle yapılan kaynaklı birleştirmelerde herhangi bir koruyucu gaz, ilave bir kaynak metali ya da kaynak ağzı açılmasına gerek bulunmamaktadır [15-18].

Literatürdeki çalışmalara bakıldığında; Boz ve Kurt [19] yaptıkları araştırmada Al ve alaşımlarının SKK işleminde farklı karıştırıcı uç profillerinin kaynaklı yapının mekanik özelliklerine ve mikro yapıları üzerine etkilerini incelemişlerdir. Tozaki ve arkadaşları [20] çalışmalarında, Al ve alaşımlarının sürtünme karıştırma nokta kaynağında farklı takım geometrilerinin kaynaklı birleştirmenin mekanik özelliklerini ve mikro yapısını etkilediğini tespit etmişlerdir. Choi ve arkadaşları [21] araştırmalarında Al alaşımlarının sürtünme karıştırma nokta kaynağında, takım geometrisinin kaynaklı yapının mekanik özelliklerine etkilerini belirlemişlerdir. Yadava ve arkadaşları [22] yaptıkları çalışmada, takım ucu profilinin, Al alaşımlarının SKK işlemi sırasında malzeme akışını ve kaynak sonrası kaynaklı birleştirmenin mekanik özelliklerini ve mikro yapılarını etkilediğini ortaya koymuşlardır. Bahrami ve arkadaşları [23] çalışmalarında; AA7075/SİC kompozit malzemenin SKK işleminde takım geometrisinin mekanik özellikler ve mikroyapı üzerine etkilerini saptamışlardır. Singh ve arkadaşları [24] yürüttükleri araştırmada Al alaşımlarının SKK sırasında farklı takım profillerinin kaynaklı birleştirmede görülen kusurlar üzerine etkilerini ele almışlar ve hatasız bir birleştirme için uygun takım profilini belirlemişlerdir.

Bu çalışmada; EN AW-5754 ve EN AW-5083 alüminyum levhalar vidalı, konik ve silindirik karıştırıcı uçlu üç farklı profildeki takımla, sürtünme karıştırma kaynağı ile birleştirilmişlerdir. Çalışmada; kaynak işlemleri sırasında omuz açısı, ilerleme hızı ve devir sayıları sabit tutularak, farklı karıştırıcı uç profillerinin; kaynaklı yapının mekanik özellikleri ve mikro yapı değişimleri üzerine etkilerinin tespit edilmesi ve bu çalışmaya en uygun takım profilinin belirlenmesi amaçlanmıştır.

\section{Materyal ve metot}

\subsection{Deneylerde kullanılan malzemeler}

$\mathrm{Bu}$ çalışmada ana malzeme olarak EN AW 5754 ve EN AW-5083 serisi $4 \mathrm{~mm}$ kalınlığındaki Al alaşımı levhalar kullanılmıştır. Tablo 1'de EN AW 5754 ve EN AW$5083 \mathrm{Al}$ alaşımlarının kimyasal bileşimleri verilmiştir.

Tablo 1. Alüminyum malzemelerin kimyasal bileşimleri.

\begin{tabular}{|c|c|c|c|c|c|c|c|c|}
\hline Element & $\mathrm{Si}$ & $\mathrm{Fe}$ & $\mathrm{Mn}$ & $\mathrm{Mg}$ & $\mathrm{Cu}$ & $\mathrm{Ti}$ & $\mathrm{Cr}$ & $\mathrm{Zn}$ \\
\hline EN AW-5754 & 0,093 & 0,191 & 0,164 & 2,774 & 0,003 & 0,007 & 0,004 & 0,007 \\
\hline EN AW-5083 & 0,112 & 0,318 & 0,535 & 4,783 & 0,073 & 0,012 & 0,062 & 0,128 \\
\hline
\end{tabular}

Çalışmada kullanılan EN AW 5754 ve EN AW-5083 Al alaşımlarının mekanik özellikleri Tablo 2'de sunulmuştur. 
Tablo 2. Alüminyum malzemelerin mekanik özellikleri.

\begin{tabular}{|c|c|c|c|c|}
\hline Malzeme & Çekme (MPa) & Akma (MPa) & Uzama (\%) & Sertlik HB \\
\hline EN AW-5754 & 198,4 & 108.6 & 25 & 52 \\
\hline EN AW-5083 & 239,1 & 159,5 & 20,1 & 75 \\
\hline
\end{tabular}

\subsection{Deneylerde kullanilan takımlar}

Bu çalışmada, üç farklı karıştırıcı uç geometrisine sahip takım kullanılmıştır. Kaynak işlemi yapılırken kaynak yapılan parçalarla temas halinde olan karıştırıcı uçta yüksek sıcaklıklar oluşmaktadır. İşlem sırasında yüksek sıcaklıklar nedeniyle oluşacak olan aşınmayı engellemek ve sertlik direncini koruyabilmek için takım malzemesi olarak 1.3343 tip yüksek hız çeliği seçilmiştir. Üretimi yapılan takımlara 1sıl işlem uygulanarak, 62 HRC sertlik değeri kazandırılmıştır. Şekil 1'de SKK da kullanılan farklı karıştırıcı uç profillerine sahip takımlar ve Şekil 2'de ise bunların ölçüleri verilmiştir.

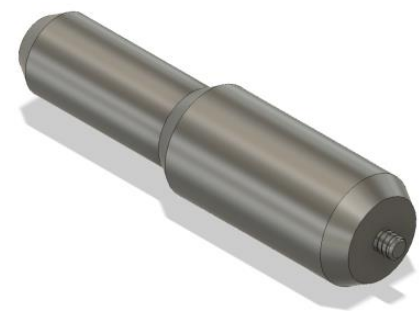

$\mathbf{a}$

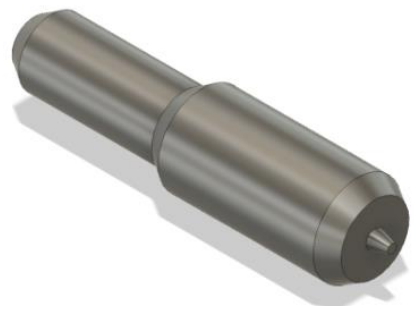

b

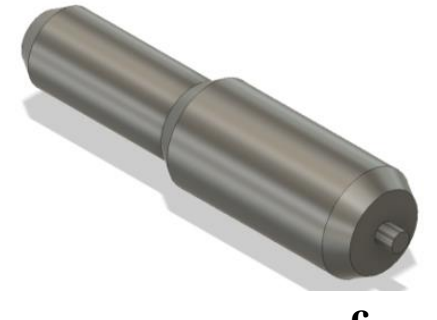

C

Şekil 1. SKK da kullanılan takımlar: a.Vidalı karıştırıcı uçlu takım b.Konik karıştırıcı uçlu takım c.Silindirik karıştırıcı uçlu takım.
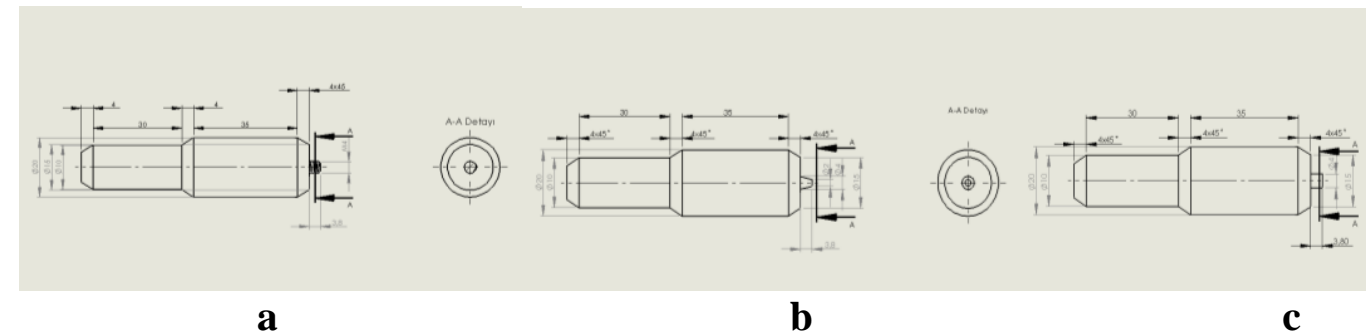

Şekil 2. Takım ölçüleri: a.Vidalı karıştırıcı uçlu takım b.Konik karıştırıcı uçlu takım c.Silindirik karıştırıcı uçlu takım.

1.343 tip yüksek hız çeliğinin kimyasal bileşenleri Tablo 3’te görülmektedir.

Tablo 3. 1.343 yüksek hız çeliğinin kimyasal bileşimi.

\begin{tabular}{|c|c|c|c|c|}
\hline $\mathrm{C}$ & $\mathrm{Cr}$ & Mo & $\mathrm{V}$ & W \\
\hline 0,90 & 4,10 & 5 & 1,90 & 6,40 \\
\hline
\end{tabular}




\subsection{SKK deneyi}

Bu çalışmada EN AW 5754 ve EN AW-5083 Al levhalar SKK metoduyla alın alına kaynak işlemi ile birleştirilmişlerdir. Kaynaklı birleştirmeler, literatür taraması sonucunda saptanan ve SKK'da mikroyapı ve mekanik davranışları üzerinde önemli etkiye sahip olan sabit devir sayısı ve ilerleme hızlarında, üç farklı pin profiline sahip takım seçilerek gerçekleştirilmiştir. Kaynak işlemi oda sicaklığında üniversal freze tezgahında gerçekleştirilmiştir. Şekil 3'de kaynak işleminde kullanılan freze tezgahı verilmiştir.

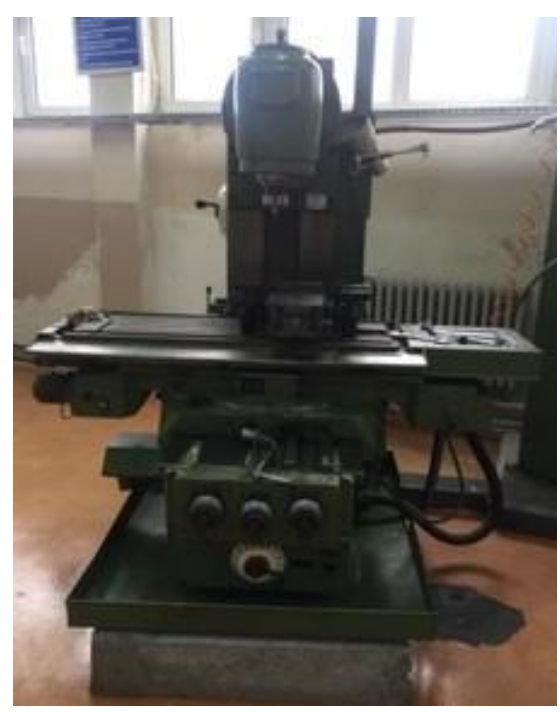

Şekil 3. Üniversal freze tezgahı.

$4 \mathrm{mmx} 100 \mathrm{mmx} 150 \mathrm{~mm}$ boyutlarındaki deney numunelerinin tüm yüzeyleri kaynak işleminden önce freze tezgahında işlenerek düzeltilip çapakları alınmıştır. Daha sonra saf alkol ile kaynak yüzeyleri silinmiştir. Kaynak öncesi hazırlıkları tamamlanan numuneler alın alına getirilerek bağlama pabuçları ile tezgaha sıkıca sabitlenmişlerdir. Karıştırıcı uç ilerleme yönüne literatüre uygun olarak daha sert bir Al alaşımı olan Al 5083, ters yöne ise Al 5754 yerleştirilmiştir. Kaynak işlemleri $450 \mathrm{~d} /$ dak devir sayısında, $50 \mathrm{~mm} /$ dak ilerleme hızında, $60 \mathrm{sn}$ bekleme süresinde, 0 derecelik omuz açısıyla ve takım dönme yönü saat yönünde seçilerek gerçekleştirilmiştir. Çalışmada kullanılan takımların uç profilleri haricindeki diğer geometrik özellikleri aynıdır. Şekil 4'de kaynaklı numunelere ait yüzey resimleri yer almaktadır.

Çalışmada, kaynaklı numunelerin optik mikroskop görüntüleri alınarak metalurjik yapıları incelenmiştir. Optik mikroskop görüntüleme için polyester kalıba alınan numuneler, zımparalama işlemine tabi tutulup, elmas pasta ile parlatılarak, Poulton ayracı (50 ml poulton çözeltisi $+25 \mathrm{ml}$ konsantre $\mathrm{HNO}_{3}+40 \mathrm{ml}$ kromik asit çözeltisi) ile dağlanmıştır.

SKK işlemi sonrasında numunelere Zwick Roel marka çekme testi cihazında oda sıcaklığında çekme testleri yapılmıştır.

SKK ile birleştirilen parçaların sertlik değerleri Shimadzu HMV marka mikro sertlik test cihazında, Vickers ölçeğinde (HV0.1) kaynak yüzeyinde kaynak dikiş yönüne dik bir hat boyunca ölçülmüştür. Ölçüm yükü $0,1 \mathrm{~kg}$ ve ölçümlerde bekleme süresi 5 sn'dir. 


\section{Bulgular ve tartışma}

Şekil 4'de verilen SKK ile birleştirilen numunelere ait kaynak yüzeyleri verilmektedir. Yüzeyler incelendiğinde vidalı ve konik karıştırıcı uçla birleştirilmiş olan kaynaklı numunelerin görüntülerinde herhangi çatlak veya gözeneğin olmadığ 1 , dikiş yüzey pürüzlülüklerinin düzgün ve birbirlerine yakın olduğu görülmektedir. Silindirik karıştırıcı uçla birleştirilmiş numunelerin görüntülerinde ise kaynak dikişinde boşluklar ve yüzeyde pürüzlülükler dikkati çekmektedir. Makro görüntülerden elde edilen sonuçlar ile çekme testinden elde edilen sonuçlar birbirlerini destekler niteliktedir. Benzer şekilde literatürde yapılan çalışmalarda da kaynak hatalarının çekme mukavemet değerlerini olumsuz yönde etkilediği ifade edilmektedir [9].

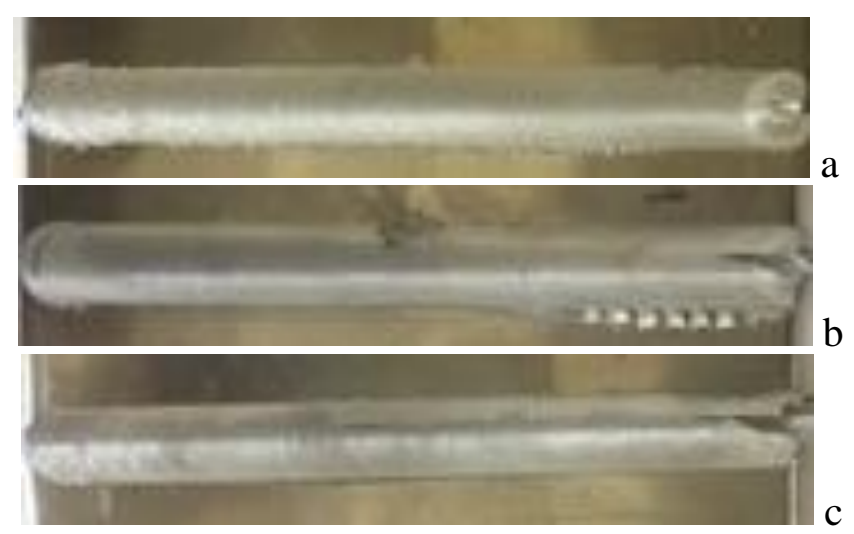

Şekil 4. Kaynaklı numunelere ait yüzey resimleri: a. Vidalı karıştırıcı uç b. Konik karıştırıcı uç c. Silindirik karıştırıcı uç.

SKK işlemi sırasında yoğun plastik deformasyon ve maruz kalınan yüksek sıcaklık, karıştırma bölgesinde yeniden kristalleşmeye ve karıştırma bölgesinin etrafinda çökeltilerin çözülmesine ve kabalaşmasına neden olur[7]. Böylece kaynak bölgesinde oluşan içyapı, dinamik olarak yeniden kristalleşen bölge (DKB), termomekanik olarak etkilenen bölge (TEB) ve 1sı etkisi altındaki bölge (IEB) olarak üçe ayrılmaktadır. Bu bölgelerin boyutu ve şekli; seçilen kaynak parametrelerine bağlı olduğu gibi karıştırıcı uç geometrisine de bağlıdır. Bu nedenle tercih edilen uç geometrisinin kaynaklı yapının mekanik davranışları üzerinde önemli etkisi bulunmaktadır. Farklı geometrilerde yapılan birleştirmelerde kaynak bölgesi optik mikroskop görüntüleri Şekil 5' te sunulmuştur. Optik mikroskop görüntüleri incelendiğinde; SKK ile birleştirilen numunelerin kaynak dikiş bölgesinde küçük taneli bir yap1 görülmektedir. En düşük kaynak dayanımı değerini veren silindirik geometrili karıştırıcı uçla birleştirilen kaynak numunesinde, kaynak bölgesinde Al 5754 tarafında boşluk (porozite) görülmektedir. Bu kusurlar kaynak dayanımını düşürmektedir. Bunun nedeni karıştırıcı uç tasarımındaki hatalardan kaynaklanmaktadır. Vidalı ve konik uçla yapılan SKK işleminde ucun karıştırılan malzemeyle temas alanı, silindirik uca göre daha fazladır. Dolayısıyla SKK işleminde ucun karıştırma yüzey alanı arttıkça, kaynak mukavemeti de artmaktadır. Artan sıcaklıkla viskoz haldeki malzemede karıştırıcı uç yardımı ile ekstrüzyon derecesi artmaktadır. Bu sebeple kaynak dikişi bölgesinde şiddetli ekstrüzyon sonucu tane küçülmesi ve pekleşmenin etkin olduğu bir yapı ortaya çıkmaktadır [3,6,15]. 


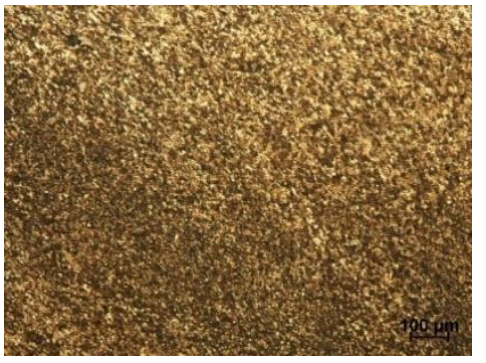

a

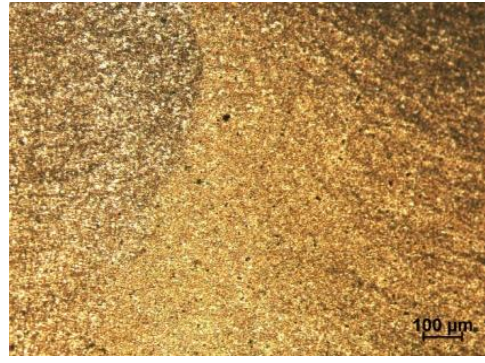

b

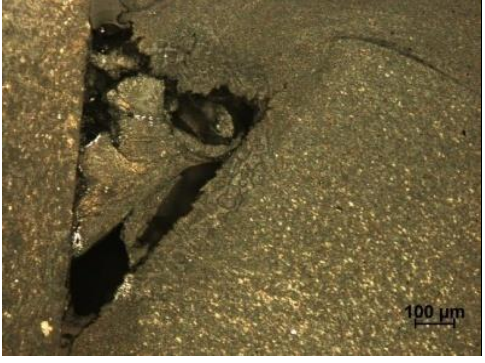

c

Şekil 5. Optik mikroskop görüntüleri: a. Vidalı karıştırıcı uç b. Konik karıştırıcı uç c. Silindirik karıştırıcı uç.

Şekil 6'da vida karıştırıcı uçla birleştirilen numunenin kaynak bölgesinden alınan mikroyap1 görüntüsü görülmektedir. Sekil incelendiğinde ince taneli yapıya sahip DKB bölgesi ile uzayan ve yönlenen tanelerden oluşan TEB bölgesi birbirinden çizgi halinde ayrılmaktadır. Her iki bölgede oluşan tane yapıları uç profil geometrilerinin etkisi ile farklılıklar göstermektedir. Kaynak esnasında oluşan deformasyon ve ekstrüzyon şiddeti, bütün kaynaklı bağlantıların DKB'sinde tanelerin küçülmesine neden olurken, TEB bölgesinde ise DKB de oluşan ekstrüzyonun neden olduğu yüksek sıcaklık; bu bölgedeki tanelerin irileşerek deforme olmasına ve yassılaşmasına neden olmaktadır.

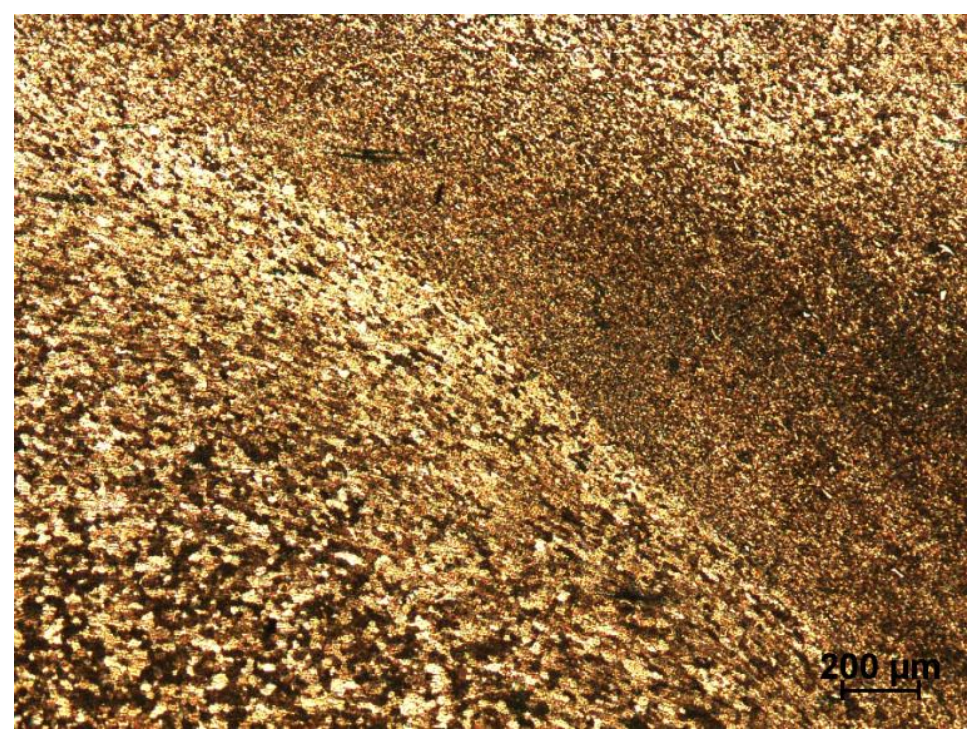

Şekil 6. Vidalı karıştırıcı uçla birleştirilen numuneye ait optik mikroskop görüntüsü.

Şekil 7'de konik karıştırıcı uçla birleştirilen numunenin kaynak bölgesinden alınan mikroyapı görüntüsü görülmektedir. DKB ile TEB birbirinden net olarak ayrılmaktadır. Görüntüde konik geometrili karıştırıcı uç ile birleştirilen numunenin DKB bölgesinde, uçtaki dönme hareketinden kaynaklandığı düşünülen halkalar görülmektedir. $\mathrm{Bu}$ halkalara soğan halkaları adı verilir[25]. Konik uçlu kaynaklı birleştirmenin DKB bölgesinin yanında yer alan TEB bölgesinde maruz kaldığı yüksek sıcaklık ve plastik deformasyonun etkisiyle tane yapılarında irileşme ve yönlenmeler meydana gelmektedir. Bu yönlenmiş taneler, DKB bölgesinin hemen yanında deformasyon bandı olarak şekilde görülmektedir. 


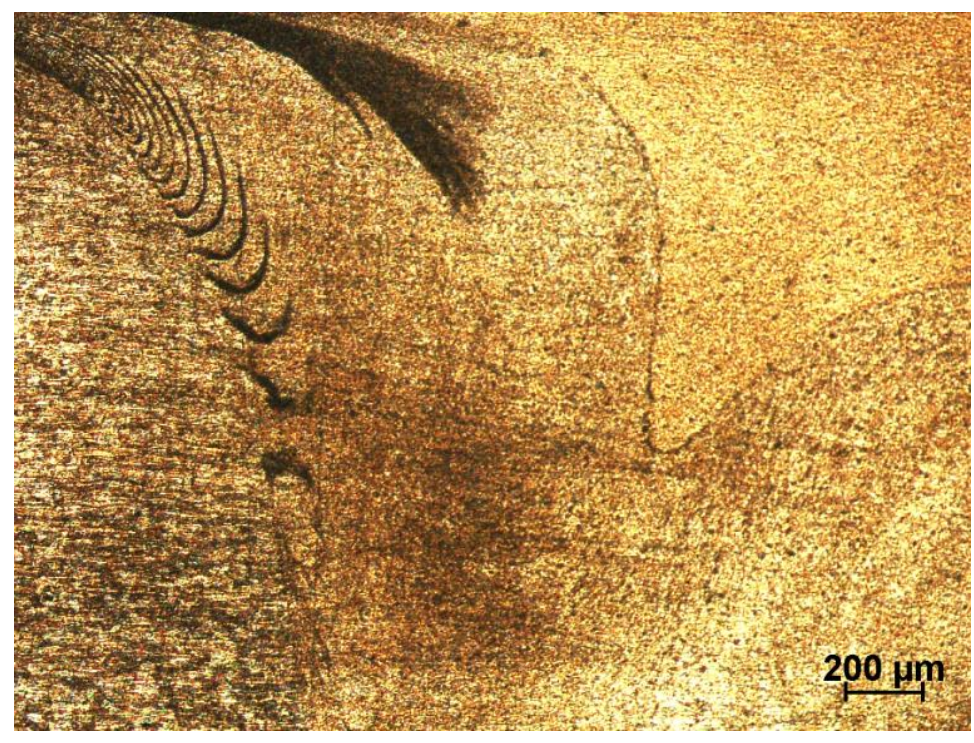

Şekil 7. Konik karıştırıcı uçla birleştirilen numuneye ait optik mikroskop görüntüsü.

IEB kaynaklı malzemenin en zayıf ve en az sertliğe sahip bölgesidir. Bu bölge sıcaklığa maruz kaldığı için, çökelti partikülleri büyümeye devam eder ve aşırı yaşlanma ya da kabalaşma gösterir bu nedenle partiküller arasındaki mesafe artar dolayısıyla da dislokasyonlar bu bölgede hiçbir engele çarpmadan kolaylıkla ilerleyerek mukavemeti düşürürler. Uygulanılan çekme testlerinde kopma hep bu bölgede gerçekleşmiştir. İncelenilen daha önce yapılmış çalışmalarda da çekme test sonuçlarında aynı bölgede kopma oluştuğu görülmüştür[26-28]. Çekme testi sonuçlarına göre, vidalı karıştırıcı uçla kaynaklanan çekme numuneleri en yüksek çekme mukavemetini (188,76 MPa) göstermişlerdir. Silindirik karıştırıcı uçla birleştirilen çekme numuneleri ise, en düşük çekme mukavemetini $(115,59 \mathrm{MPa})$ göstermişlerdir. Bu değerler tüm numuneler içerindeki en düşük çekme muvamet değerleri olup bu düşük çekme mukavemet değerleri kaynak dikişinde meydana gelen kaynak hatalarından kaynaklandığ 1 düşünülmektedir[9]. Çekme testlerinde tüm numunelerde kırılmalar daha düşük mekanik özelliklere sahip Al 5754 tarafında ve IEB'de tek taraflı boyun vererek meydana gelmiştir. Takım karıştırıcı uç profilinin kaynak mukavemeti üzerine etkisi Şekil 6'da görülmektedir.

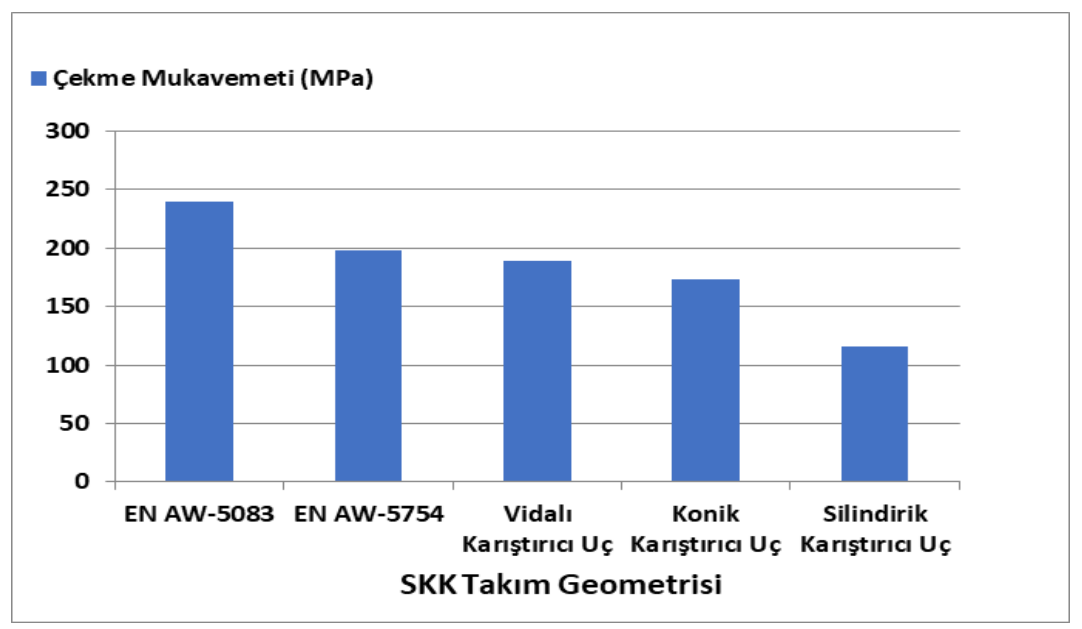

Şekil 6. Takım karıştırıcı uç profilinin kaynak mukavemeti üzerine etkisi. 
Şekil 7'de kaynak bölgesinden alınmış mikrosertlik değerleri görülmektedir. Şekil incelendiğinde, tüm numunelerde kaynak merkez sertliğinin esas malzeme sertliğinden daha yüksek olduğu görülmektedir. Bunun sebebinin; AA5XXX Al alaşımlarının SKK işlemi sırasında kaynak bölgesinde ortaya çıkan $\mathrm{Al}_{\mathrm{x}}(\mathrm{Fe}, \mathrm{Mn})_{\mathrm{y}} \mathrm{Si}_{\mathrm{z}}, \mathrm{Al}_{\mathrm{x}}(\mathrm{Fe}, \mathrm{Mn})$ ve $\mathrm{Mg}_{\mathrm{x}} \mathrm{Si}$ intermetalik fazlarından kaynaklandığı düşünülmektedir[6,29]. Özellikle silindirik karıştırıcı uçla yapılan deney numunelerinde sertlik değerinin yüksek olması, bu numunelerin çekme dayanımını önemli ölçüde düşürmektedir.

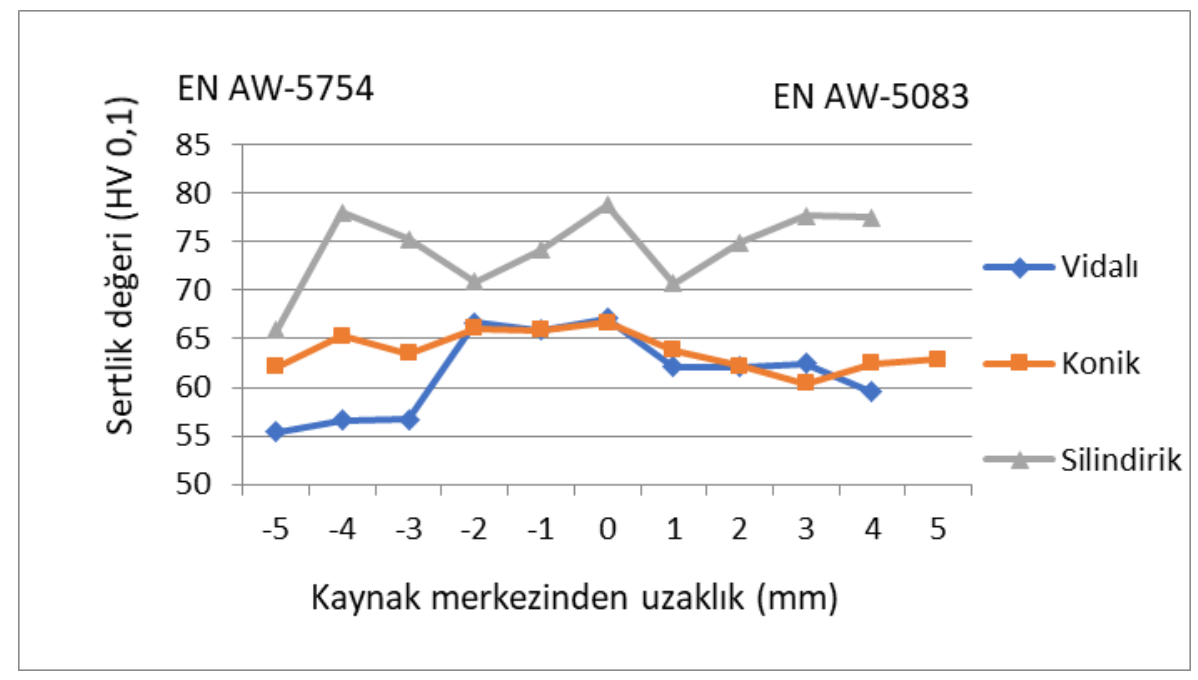

Şekil 7. Numunelere ait sertlik değerleri.

\section{Sonuçlar}

$\mathrm{Bu}$ çalışmada aşağıdaki sonuçlar elde edilmiştir:

1. EN AW-5754 ve EN AW-5083 alüminyum alaşımları başarılı bir şekilde SKK yöntemi ile birleştirilebilmektedir.

2. Optik mikroskop görüntüleri incelendiğinde; vidalı ve konik karıştırıcı uçla birleştirilen numunelerde kaynak bölgesinde düzgün bir karışım görülmektedir. Silindirik karıştırıcı uçla birleştirilen numunede, kaynak bölgesinde boşluklar görülmektedir. Bu boşluklar kaynak dayanımını düşürmektedir.

3. En yüksek kaynak dayanımı $(188,76 \mathrm{MPa})$ vidalı karıştırıcı uçla birleştirilen numunelerde, en düşük kaynak dayanımı $(115,59 \mathrm{MPa})$ ise silindirik karıştırıcı uçla birleştirilen numunelerde görülmektedir.

4. Tüm numunelerde kaynak merkez sertliğinin esas malzeme sertliğinden daha yüksektir. Bunun sebebinin AA5XXX Al alaşımlarının SKK işlemi sırasında kaynak bölgesinde ortaya çıkan $\mathrm{Al}_{\mathrm{x}}(\mathrm{Fe}, \mathrm{Mn})_{\mathrm{y}} \mathrm{Si}_{\mathrm{z}}, \mathrm{Al}_{\mathrm{x}}(\mathrm{Fe}, \mathrm{Mn})$ ve $\mathrm{Mg}_{\mathrm{x}} \mathrm{Si}$ intermetalik fazlarından kaynaklandığ düşünülmektedir.

5. Mikrosertlik değerleri uç geometrisine göre değişmektedir. Tüm numunelerde kaynak dikişi sertliğinin esas malzeme sertliğinden daha yüksek olduğu tespit edilmiştir. Özellikle silindirik karıştırıcı uçla birleştirilen deney numunelerinde sertlik değerinin yüksek olması, bu numunelerin çekme dayanımını önemli ölçüde düşürmektedir.

6. Yapilan incelemeler sonucunda, EN AW 5754 ve EN AW-5083 alüminyum alaşımlarının SKK ile birleştirilmesinde vidalı karıştırıcı uç geometrili takım önerilmektedir. 


\section{Teşekkür}

Bu çalışma Aydınlar Metal Sanayi ve Ticaret A.Ş. tarafından desteklenmiştir.

\section{Kaynaklar}

[1] Türker, E., Alüminyum ve alaşımlarının dökümünde rafinasyon yöntemlererinin karşılaştırılması, Yüksek Lisans Tezi, İstanbul Teknik Üniversitesi, Fen Bilimleri Enstitüsü İstanbul, (2005).

[2] Johansen, H.G., Structural aluminium materials. TALAT Lecture 2202, European Aluminium Association, (2005).

[3] Çam, G., Sürtünme karıştırma kaynağı (SKK): Al alaşımları için geliştirilmiş yeni bir kaynak teknolojisi, Mühendis ve Makine, 46, 541, 40-51, (2005).

[4] Hwang, Y.M., Fan, P.L ve Lin, C.H., Experimental study on friction stir welding of copper metals, Journal of Materials Processing Technology, 210, 1667-1672, (2010).

[5] Muthu, M.F.X. ve Jayabalan, V., Tool travel speed effects on the microstructure of friction stir weldedaluminum-copper joints, Journal of Materials Processing Technology, 217, 105-113, (2015).

[6] Gürel Çam, Selçuk Mistıkoğlu, Recent developments in friction stir welding of al-alloys, Journal of Materials Engineering and Performance, 23, 6, 19361953, (2014).

[7] Dalkılıç, S., Sürtünme karıştırma kaynağı ve havacılık ve uzay endüstrisindeki uygulama alanları, Havacılık ve Uzay Teknolojileri Dergisi, 5, 25-33, (2012).

[8] Şık, A., Sürtünme karıştırma kaynağı ile birleştirilen alüminyum levhalarının eğme ve yorulma özelliklerinin incelenmesi, SAÜ Fen Bilimleri Dergisi, 9,2, 12-17, (2005).

[9] Başar, G. ve Mistıkoğlu, S., Kaynak parametrelerinin sürtünme karıştırma kaynağı ile birbirine kaynaklanmış Cu/Al-1050 mekanik özellikleri üzerindeki etkilerinin incelenmesi, El-Cezerî Fen ve Mühendislik Dergisi, 4, 2, 282-290, (2017).

[10] Mohammadi, J., Behnamian, Y., Mostafaei, A., Izadi, H., Saeid, T., Kokabi, A.H. ve Gerlich, A.P., Friction stir welding joint of dissimilar materials between AZ31B magnesium and 6061 aluminum alloys: Microstructure studies and mechanical characterizations, Materials Characterization, 101, 189-207, (2015).

[11] Sharma, H.K., Bhatt, K.,, Shah, K. Ve Joshid, U., Experimental analysis of friction stir welding of dissimilar alloys AA6061 and Mg az31 using circular butt joint geometry, 3rd International Conference on Innovations in Automation and Mechatronics Engineering, ICIAME, India, 566-572 (2016).

[12] Padhy, G.K., Wu. ve C.S. Gao,S., Friction stir based welding and processing technologies - processes,parameters, microstructures and applications: A review, Journal of Materials Science \& Technology, 34, 1-38, (2018).

[13] Gangwar, K. ve Ramulu, M., Friction stir welding of titanium alloys: A review, Materials and Design, 141, 230-255, (2018).

[14] Kumar, R., Singha, R., Ahujab, I.P.S., Pennac, R. ve Feo, L., Weldability of thermoplastic materials for friction stir welding- A state of art review and future applications, Composites Part B, 137,1-15, (2018).

[15] Başak, H., Kayır, H. ve Türkyılmaz, E.H., Sürtünme karıştırma kaynağında farklı karıştırma uç formlarının oluşturduğu kuvvetlerin ve birleşmeye etkisinin 
deneysel incelenmesi, El-Cezerî Journal of Science and Engineering, 4, 2, 249-257, (2017).

[16] Ranjan, R., Khan, A.R., Parikh, C., Jain, R., Mahto, R.P., Pal, P., Pal, S.K. ve Chakravarty, D., Classification and identification of surface defects in friction stir welding: An image processing approach, Journal of Manufacturing Processes, 22, 237-253, (2016).

[17] Bayazid, S.M., Farhangi, H. ve Ghahramani, A., Investigation of friction stir welding parameters of 6063-7075 aluminum alloys by taguchi method, Procedia Materials Science, 11, 6 - 11, (2015).

[18] Arıcı, A.A. ve Ertürk, A.T., Sürtünme karıştırma kaynağı ile birleştirilen polietilen levhalarda kaynak bölgesi özelliklerinin belirlenmesi, 8. Uluslararası Kırılma Konferansı Bidiri Kitabı, İstanbul, 490-497, (2007).

[19] Boz, M. ve Kurt, A., The influence of stirrer geometry on bonding and mechanical properties in friction stir welding process, Materials \& Design, 254, 343-347, (2004).

[20] Tozaki, Y., Uematsu Y. ve Tokaji, K., Effect of tool geometry on microstructure and static strength in friction stir spot welded aluminium alloys, International Journal of Machine Tools and Manufacture, 47, 15, 22302236, (2007).

[21] Choi, D.H., Ahn, B.W., Lee, C.Y., Yeon, Y.M., Song, K. ve Jung, S.B., Effect of pin shapes on joint characteristics of friction stir spot welded AA5J32 sheet, Materials Transactions, 51,5, 1028-1032, (2010).

[22] Yadava, M.K., Mishra, R.S., Chen, Y.L., Carlson, B. Ve Grant, G.J., Study of friction stir welding of thin aluminium sheets in lap joint configuration, Journal Science and Technology of Welding and Joining, 15, 1, 70-75, (2010).

[23] Bahrami, M., Givi, M.K.B., Dehghani, K. ve Parvin, N., On the role of pin geometry in microstructure and mechanical properties of AA7075/SiC nanocomposite fabricated by friction stir welding technique, Materials \& Design, 53, 519-527, (2014).

[24] Singh, A., Kumar, V. ve Grover, N.K., Influence of tool pin profiles on friction stir welding with a gap for AA6082-T6 aluminium alloy, Materials Research Express, 6, 8, (2019).

[25] Lee, W. B., Yeon, Y. M. ve Jung, S. B., Evaluation of the microstructure and mechanical properties of friction stir welded 6005 aluminum alloy, Materials Science and Technology, 19, 513-518, (2003).

[26] Kafalı, H., ve Ay, N., Sürtünme karıştırma kaynağı ile birleştirilmiş havacılık ve uzay yapılarında kullanılan Al 6013-T6 alaşımınınmikroyapı ve mekanik özelliklerinin incelenmesi, Havacılık ve Uzay Teknolojileri Dergisi, 7, 2, 85101, (2014)

[27] Elangovan, K. ve Balasubramanian, V., "Influences of post-weld heat treatment on tensile properties of friction stir-welded AA6061 aluminium alloy joints," Materials Characterization, 59, 9, 1168-1177, (2008).

[28] Şık, A., KAyabaş, Ö., Sürtünme karıştırma kaynağı ile yapılan alüminyum kaynağında kaynak bölgesinin mekanik özelliklerinin incelenmesi, Gazi Üniversitesi Endüstriyel Sanatlar Eğitim Fakültesi Dergisi, 11, 12, 30-43, (2003).

[29] Attallah, M.M., Davies, C.L. ve Strangwood, M., Influence of base metal microstructure on microstructural development in aluminium based alloy friction stir welds, Science and Technology of Welding and Joining., 12, p 361-369, (2007). 